\title{
Reuse the pulp and paper industry wastewater by using fashionable technology
}

\author{
K. Sudarshan ${ }^{1}$ (D) K. Maruthaiya ${ }^{2} \cdot$ P. Kotteeswaran ${ }^{3} \cdot$ A. Murugan ${ }^{1}$
}

Received: 2 April 2016/ Accepted: 16 September 2016/Published online: 30 September 2016

(c) The Author(s) 2016. This article is published with open access at Springerlink.com

\begin{abstract}
This proposed method is a promising way, which can be implemented in pulp and paper industries by effective removal of the color and chemical oxygen demand (COD) and the resulting treated water may surely reuse to the other streams. Fourier Transformer Infra Red spectra confirmed the presence of the respective functional groups in the removed pollutants from the wastewater. The efficiency of Non-ferric Alum (NF Alum) and cationic polyacrylamide (C-PAM) with and without power boiler fly ash was also studied. The reduction efficiency of color and chemical oxygen demand (COD) is evaluated at the optimum dosage of NF Alum, fly ash, and C-PAM. At the optimized $\mathrm{pH}$ attained from these coagulants using to treat the wastewater, the flocs formation/settling and the pollutant removal efficiency are encouraging and the resulting color of the wastewater is to $40 \mathrm{PtCo}$ units from $330 \mathrm{PtCo}$ units and COD to $66 \mathrm{mg} / \mathrm{L}$ from $218 \mathrm{mg} / \mathrm{L}$. While using NF Alum alone with C-PAM for the treatment of wastewater, the highest reduction efficiency of COD is $97 \mathrm{mg} / \mathrm{L}$ from $218 \mathrm{mg} / \mathrm{L}$ and the color is 60 from $330 \mathrm{PtCo}$ units at $\mathrm{pH} 4.8$ was noted. From these observations, NF Alum and power boiler fly ash with C-PAM can effectively
\end{abstract}

Electronic supplementary material The online version of this article (doi:10.1007/s13201-016-0477-1) contains supplementary material, which is available to authorized users.

K. Sudarshan

ksudarshantnpl@gmail.com

1 Department of Chemistry, Kalasalingam University, Srivilliputhur 626126, India

2 R\&D and Environment, Tamilnadu Newsprint and Papers Limited, Karur 639136, India

3 Department of Chemistry, SCAD College of Engineering and Technology, Tirunelveli 627414, India remove the pollutants from the pulp and paper mill wastewater and the water can be reused for other streams.

Keywords Cationic polyacrylamide Chemical oxygen demand · Color · Fly ash · Non-ferric alum

\section{Introduction}

The pulp and paper mill effluent formed at the mill is made up of large number of component streams and it generates different varieties of pollutant. Pulp mill bleach plant wastewater is the major source of the pollutant in pulp and paper industries (Razali et al. 2012). Because of the chemicals used in the pulping and bleaching processes, such as sodium hydroxide, sodium carbonate, sodium sulfide, chlorine dioxide or elemental chlorine, hydrogen peroxide, sulphuric acid, etc., (Kamali and Khodaparast 2015). During bleaching of the pulp, the main aim is to be the removal of lignin (Sunakar et al. 2012). Lignin is a complex, highly cross-linked hydroxylated, and methoxylated organic polymer (Garg et al. 2004). During the cooking stage, the most of the lignin have been removed in the form of black liquor and it burned in the recovery boiler to generate energy and spent chemicals. The remained lignin has been eliminated during bleaching stages and it drained as effluent/wastewater.

The pulp mill wastewater contains varieties of organic compounds, such as chlorinated phenols, resin acids, chlorinated lignins, unsaturated fatty acids, carboxylic acids, terpenes, and other organics, which contains chlorine/sulphur compounds (Kumar et al. 2014). In addition, it contains nitrogen and phosphorus compounds and the source is wood as a raw material. Water is also used for process cooling, equipment cleaning, general facilities 
operations, and to generate steam for use in processes and on-site power generation. During bleaching, chromophoric and highly oxidized polymeric lignin derivatives are formed that give rise to a dark colorization in the wastewater (Choudhary et al. 2013; Sahoo and Gupta 2005). Therefore, the pulp and paper industries have several treatment systems, such as anaerobic treatment, activated sludge lagoon, clarifier system for remove organics, and inorganic substances from the wastewater and to meet the effluent discharge standards.

\section{Project background}

The use of inorganic salts for coagulation-flocculation has been well documented. Now, the trend is also moving towards this technique as fashion for pulp and paper mill wastewater treatments. Kumar et al. (2011) have been investigated a comparative study for treatment of this type of effluent using various coagulants, such as aluminum chloride, polyaluminum chloride, and copper sulphate. They observed that PAC reduced COD to 84 and $92 \%$ of color was removed at an optimum $\mathrm{pH} 5$, aluminum chloride reduced $74 \% \mathrm{COD}$ and $86 \%$ color at an optimum $\mathrm{pH}$ 4 , and copper sulphate reduced COD to $76 \%$ and color to $78 \%$ at an optimum $\mathrm{pH} 6$.

Srivastava et al. (2005) were observed that polyaluminum chloride (PAC) as a coagulant and bagasse fly ash as an adsorbent for the removal of COD and color are 80 and $90 \%$, respectively, at optimum $\mathrm{pH} 3$. Ahmad et al. (2008) were studied the efficiency of alum and polyaluminum chloride (PAC) when used alone and in coupled with cationic polyacrylamide (C-PAM) and anionic polyacrylamide (A-PAM) on the treatment of pulp and paper mill wastewater. They found that Alum coupled with C-PAM is the best system and it gives $99.7 \%$ reduction of turbidity, $99.5 \%$ removal of TSS, and $95.6 \%$ reduction of COD.

Some researchers treated pulp and paper mill wastewater by the electrochemical degradation method followed by coagulation/flocculation, ozone treatment, and biological methods for COD and color removal but mostly not deal with reuse of the resources. Coagulation/flocculation are not only the economic but also the effective method for removal of COD and color from pulp and paper mill wastewater (Nawaz et al. 2014). The treatment using this method is fashion; because of these processes, it is a promising way of removal of pollutants in short reaction time (Tzoupanos and Zouboulis 2008).

Nowadays, resource recovery is a main thing, especially water resource is very important in all types of industries. In this work, an effort has been made to reuse after treating the huge volume of $\left(\sim 32000 \mathrm{M}^{3}\right.$ per day) wood and bagasse-based integrated pulp and paper mill wastewater by NF Alum and fly ash along with C-PAM through the coagulation-flocculation method. Some researchers have been worked with the alum and C-PAM for wastewater treatment (Wong et al. 2006). However, the major drawback is not able to reduce the total dissolved solids during the treatment and hence possess lots of problems in water recycle and reuse. Most of the researchers deal with the total suspended solids, but not deal with total dissolved solids during wastewater treatment. However, in this work, the TDS levels are maintained in the same trend and not much enhanced due to raw material selection for treatment and find out the optimum dosage. The removal of pollutants was achieved through two simultaneous mechanisms, which includes coagulation by charge neutralization and flocculation by bridging. The removal of pollutants was proved through FTIR spectra by their functional groups. Wastewater released from this integrated pulp and paper industry is approximately 22 to $35 \mathrm{M}^{3}$ per ton of paper produced. If treated this high-colored wastewater by this proposed method, the resulting treated water may definitely reuse to other streams.

\section{Experimental}

\section{Materials}

The wastewater sample has been collected from the Secondary Clarifier Inlet (Fig. 1) in an integrated pulp and paper mill, Tamilnadu, India. Then, the water sample was characterized and the analyzed using IS 3025 (Indian Standards) standard methods at various dosages which are given in Table 1.

$p H$

For measuring $\mathrm{pH}, 100 \mathrm{ml}$ of the sample taken in a clean dry beaker stirred well until reached the stable value.

\section{COD: (standard reference: IS 3025 (Part 58)}

$0.4 \mathrm{~g}$ of Mercury(II) sulphate was placed in a reflux tube. An aliquot of sample was diluted to $20 \mathrm{ml}$ with de-mineralized (DM) water and mixed well (simultaneously for blank, used $20 \mathrm{ml}$ of DM water), and, then, add $10 \mathrm{ml}$ of $0.25 \mathrm{~N}$ standard potassium dichromate solution to the sample containing reflux tube. Finally, $30 \mathrm{ml}$ of concentrated sulphuric acid, already contains silver sulphate (prepared by $10.12 \mathrm{~g}$, silver sulphate was added to 11 of concentrate sulphuric acid, kept overnight for dissolution and shook well after dissolution), was slowly added and mixed well. Reflux the contents of the flask for $2 \mathrm{~h}$ at 
Fig. 1 Effluent treatment system layout

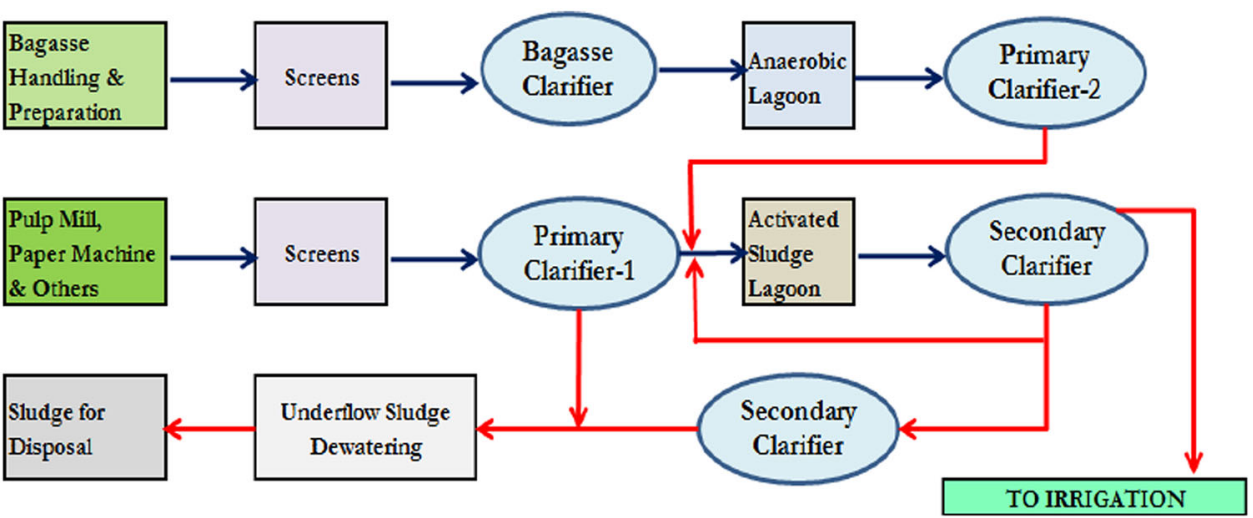

Table 1 Characteristics of the treated and untreated pulp and paper mill wastewater

\begin{tabular}{|c|c|c|c|c|c|c|}
\hline \multirow[t]{2}{*}{ Particulars } & \multirow[t]{2}{*}{ Untreated wastewater } & \multicolumn{5}{|c|}{ Treated with NF Alum:fly ash } \\
\hline & & $0.75: 1.0$ & $0.75: 1.5$ & $1: 1$ & $1.5: 1.5$ & $2: 2$ \\
\hline $\mathrm{pH}$ & 8.2 & 7.1 & 6.7 & 7.0 & 5.9 & 4.4 \\
\hline Color, Pt.Co Unit & 330 & 65 & 65 & 40 & 20 & $<20$ \\
\hline $\mathrm{COD},(\mathrm{mg} / \mathrm{L})$ & 218 & 81 & 80 & 66 & 50 & 50 \\
\hline TDS, (mg/L) & 1744 & 1755 & 1770 & 1740 & 1798 & 1784 \\
\hline
\end{tabular}

$150 \pm 2{ }^{\circ} \mathrm{C}$, then cooled and washed down the condensers with $60 \mathrm{ml} \mathrm{DM}$ water. Then, it was titrated against $0.1 \mathrm{~N}$ standard ferrous ammonium sulphate using ferroin as indicator. The end point is attained when the color changes sharply from green blue to wine red.

\section{Color: standard reference: IS 3025 (Part 4)}

Platinum-cobalt method Color is measured by visual comparison of the sample with platinum-cobalt standards. One unit of color is produced by $1 \mathrm{mg}$ of platinum per litre in the form of chloroplatinate ion. Prepare standard solutions having color units of $5,10,15$, and up to 70 as prescribed above said reference. The clear supernatant solution was taken for analysis. If the color exceeded 70 units, the sample was diluted using DM water until the color is in the range of the standard solutions.

\section{Methods}

The coagulants-flocculants were chosen by depending on the nature of the pollutants presents in the effluent. Normally, pulp and paper mills have strong anionic nature due to the major source of lignin/chromophore derivatives contained pulp mill bleach effluent.

Jar test procedures carried out using $1000 \mathrm{ml}$ of the pulp and paper mill wastewater samples with the various dosages of NF Alum and C-PAM with and without fly ash. The selected coagulants/flocculants were added to $1000 \mathrm{ml}$ of wastewater and it was stirred for a period of $3 \mathrm{~min}$ at $50 \mathrm{rpm}$ and it was followed by further slow mixing of $2 \mathrm{~min}$ at $30 \mathrm{rpm}$. The flocs formed were allowed to settle for $30 \mathrm{~min}$. After settling, the $\mathrm{pH}$, color, and COD were analyzed for the further process. This analysis was repeated for ten times for getting average values using the Indian Standards IS 3025 standard methods.

\section{Results and discussion}

Coagulants-flocculants required dose depends on the concentration of colloidal impurities present in the water. In this study, various dosages of coagulants and flocculants have been used to treat the wastewater and keeping other as a constant to find the optimum dosage level. The average test resulted and the various dosages of NF Alum and fly ash (in grams per one litre of wastewater) have been shown in Table 1.

From these observations, 1.5:1.5 grams of NF Alum: fly ash per one litre of the wastewater are the optimum dosage and to get better resulting water for reuse when compared with other dosage levels. At pH 5.9, the color has been reduced to 20 from the untreated value $330 \mathrm{PtCo}$ units and COD reduced from 218 to $50 \mathrm{mg} / \mathrm{L}$. If treating this wastewater without fly ash, maximum reduction efficiency, i.e., the color of the treated water is $60 \mathrm{PtCo}$ units and the $\mathrm{COD}$ is $97 \mathrm{mg} / \mathrm{L}$ at $\mathrm{pH} 4.8$ and it cannot be reused due to acidic nature. 
The dosage of 1:1 grams of NF Alum: fly ash per litre of the wastewater, test results showed COD, color, and total dissolved solids (TDS) of the treated water also getting better reduction efficiency at the neutral $\mathrm{pH}$.

\section{Effect of coagulants-flocculants}

The $\mathrm{pH}$ of the wastewater plays an important role, when NF Alum is used for coagulation process. Because the solubility of the aluminum species in effluent is $\mathrm{pH}$ dependent, it is generally present in the form of positive ions (i.e., $\mathrm{Al}(\mathrm{OH})^{2+}$ and $\mathrm{Al}^{3+}$ ). The NF Alum may acts as an adsorbing agent for the condensate polymer/lignin complex. When applied to the wastewater, it may hydrolyze into aluminum hydroxide forming a large, insoluble particulate with a large surface area. Concurrently, C-PAM may bind to the hydroxyl or methoxyl groups of the lignin to create an insoluble complex. We know that the lignin has methoxyl $\left(\mathrm{O}-\mathrm{CH}_{3}\right)$ groups, hydroxyl groups of primary and secondary aliphatic, phenolic hydroxyl groups, carboxyl $(-\mathrm{COOH})$ groups, and carbonyl functional groups. This complex may then be adsorbed into the hydrolyzed aluminum hydroxide and become bound forming the insoluble agglomerate and removing the color from the effluent without re-solubilizing.

The main advantage of using C-PAM is the $\mathrm{pH}$ intensive and functioning well over a broad $\mathrm{pH}$ range. The cationic charge in this polymer is derived from nitrogen in the form of a secondary, tertiary, or quaternary amine group and the charge can be located on a pendant group or may be in the backbone of the polymer chain. The addition of the NF Alum and the C-PAM reacts with the lignin in the wastewater to form flocs and remove COD and color from the effluent, thus reducing the true color of the effluent (Fig. 2). However, when used without fly ash, the better removal efficiency occurs at $\mathrm{pH} 4.8$, but it has corrosive nature due to acidic medium. In addition, it increases the TDS level in treating water. Using NF Alum and C-PAM with fly ash to treat the sample surprisingly showed that the TDS of the wastewater is not increased and maintained the same trend (Fig. 3). This is also one of the significant uses of power boiler fly ash for treating the pulp and paper mill wastewater.

In the case of using fly ash as an adsorbent, the metal salts get hydrolyzed in the presence of natural alkalinity to form metal hydroxides. The multivalent cations present in the fly ash can reduce the zeta potential value, while the metal hydroxides are good adsorbents. The carbon content of fly ash is significant, because the effectiveness of fly ash as an adsorbent improved with the increasing carbon content (Kulkarni et al. 2013). They form a monomolecular layer on the surface of suspended organic matter and remove it by trapping them and settling. So if fly ash used

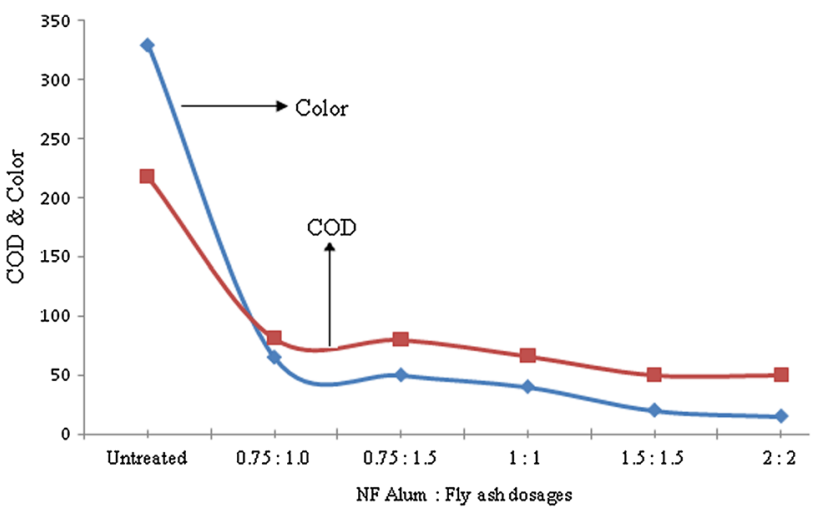

Fig. 2 Color and COD reduction in various dosages

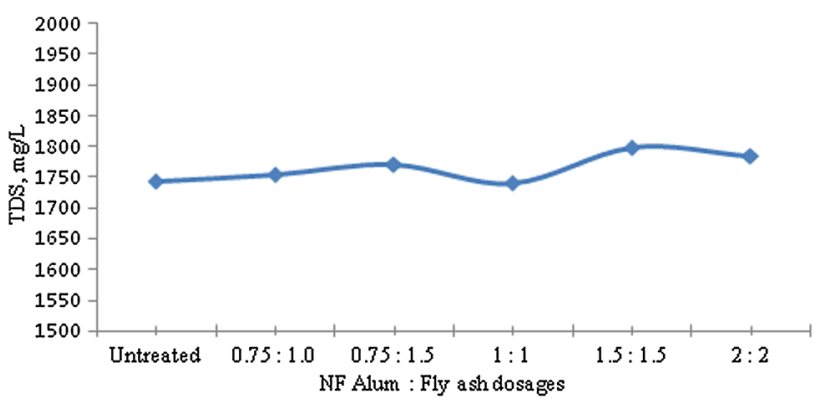

Fig. 3 TDS trend during treatment

along with NF Alum and C-PAM to treat the pulp and paper mill wastewater, it gives better results and effectively removes the pollutants and certain to reuse the treated water to other waste facilities or streams.

\section{FTIR spectral analysis}

FTIR spectroscopy is a complementary and extensively used method, and gives more information about the presence of functional groups in their respective compounds. Every lignin of IR spectra has a strong wide band between 3500 and $3100 \mathrm{~cm}^{-1}$ assigned to $-\mathrm{OH}$ bond-stretching vibrations. This band is caused by the presence of alcoholic and phenolic hydroxyl groups involved in hydrogen bonds. The spectrum (Fig. 4) of integrated pulp mill wastewater sample collected from secondary clarifier showed that the broad band at $3325 \mathrm{~cm}^{-1}$ is mainly assigned for the carbonylated and hydroxylated functional groups, i.e., $-\mathrm{O}-\mathrm{H}$ bond of hydrated phenols, poly(vinyl phenol), poly(ethylene oxide), and poly(vinyl isobutylether), and the wave number of $1635 \mathrm{~cm}^{-1}$ is assigned for $\mathrm{N}-\mathrm{H}$ bond of hydrated primary amines, amino acids, $\mathrm{C}=\mathrm{C}$ non-cyclic alkenes and cyclic alkanes, $\mathrm{C}=\mathrm{O}$ stretching of polypeptides, and urease $\mathrm{NO}_{2}$ asymmetric stretching of nitrates (Pretsch et al. 2009).

After treating this wastewater, the pollutants were reduced due to the above said functional groups are broken 


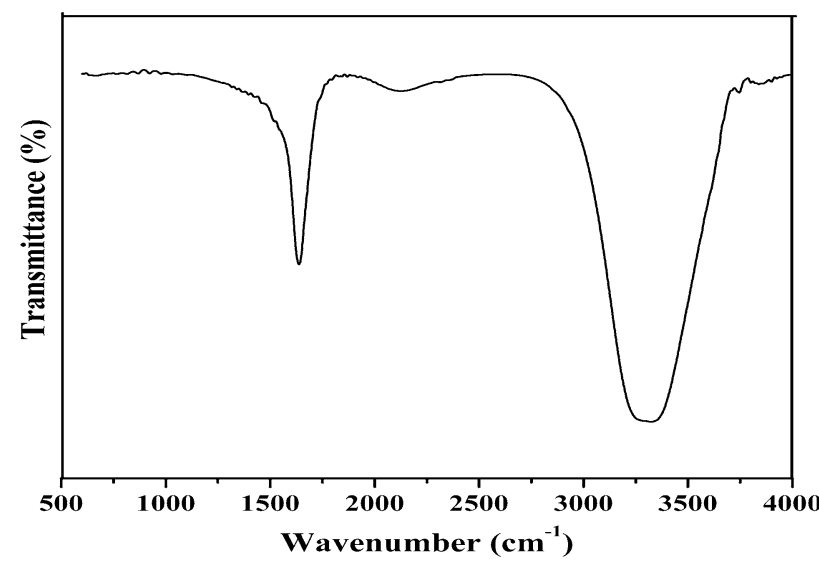

Fig. 4 FTIR spectra of untreated pulp and paper mill wastewater

and gets de-linked from waste water along with the added coagulants and flocculants. Particularly, in this research work, it was observed that the main functional group is carboxylic group in the lignin which is cause of color, and another significant functional group of the $-\mathrm{OH}$ bond from hydrated phenol, subsequently, one more $\mathrm{N}-\mathrm{H}$ bond from hydrated primary amines was segregated from the wastewater sample. These are made bond with the additives, such as NF Alum, fly ash, and C-PAM formed flocs. The broad band of the untreated sample spectra at $3325 \mathrm{~cm}^{-1}$ is observed mainly due to the alcoholic and phenolic hydroxyl groups in lignin. After treating, these functional groups are de-linked from the wastewater and it appears in the treated wastewater sludge. After the removal of the above pollutants from the pulp and paper industry wastewater, the resulting water was taken for analysis.

The removed functional groups present in the treated wastewater sludge have also been proved through the FTIR spectra (Fig. 5). The bands appeared at around $1250-900 \mathrm{~cm}^{-1}$ for the treated wastewater sludge mainly indicated the stretching vibration of cyclic ethers caused by the combination or overlapping of $\mathrm{C}-\mathrm{O}$ as a result of several deformations in lignin by the action of the chemicals used in the processes. The bands at around $1369-1316 \mathrm{~cm}^{-1}$ showed the stretching vibration of aromatic nitro compound $\left(\mathrm{NO}_{2}\right)$ and aromatic $\mathrm{C}-\mathrm{N}$ stretching caused by agricultural residues and the chemicals used in the treatment system. The band at $1395 \mathrm{~cm}^{-1}$ was assigned to the asymmetric stretching of $\mathrm{SO}_{2}$ groups appeared due to the pulping process of chemicals and gets de-linked from the wastewater due to the added coagulants. Bands appeared at 1424 and $1458 \mathrm{~cm}^{-1}$ denote the asymmetric deformation of $\mathrm{C}-\mathrm{H}$ in lignin and $\mathrm{C}=\mathrm{C}$ stretching vibration. There are also stretching vibrations of aromatic nitro compound $\mathrm{NO}_{2}$, and secondary $\mathrm{C}=\mathrm{O}$ and $\mathrm{C}-\mathrm{N}$ groups at $1540-1515 \mathrm{~cm}^{-1}$ have been observed. The band at $1648 \mathrm{~cm}^{-1}$ was observed for the secondary amide $\mathrm{C}=\mathrm{O}$

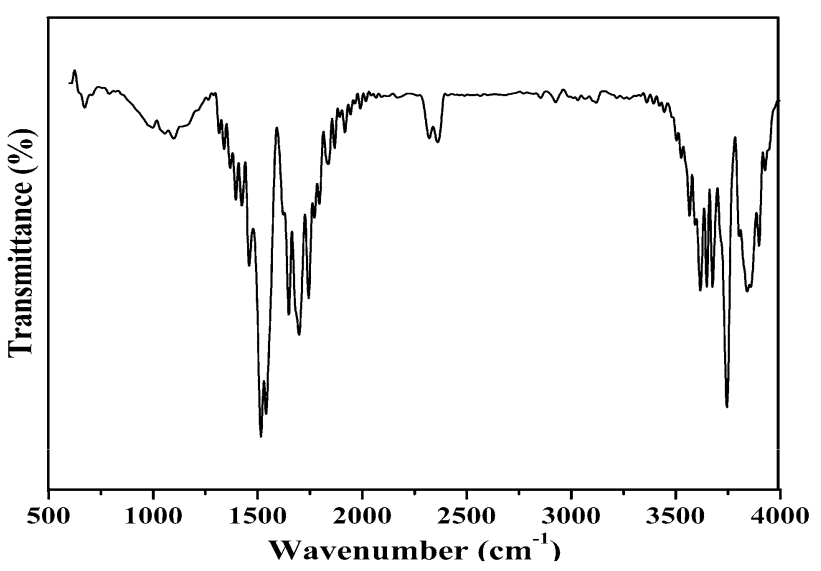

Fig. 5 FTIR spectra of treated pulp and paper mill wastewater sludge

stretching, primary amide $\mathrm{NH}_{2}$ bending, $\alpha, \beta$-unsaturated aromatic oximes/imines, and intra-molecular hydrogenbonded carboxylic acid groups. The functional groups like $\mathrm{C}=\mathrm{O}$ stretching of $\alpha$-amino acids, Aryl aldehydes, $\alpha, \beta$ unsaturated acids, carbamates, amide I band, $-\mathrm{CO}-\mathrm{NH}-$ $\mathrm{CO}-, \alpha, \beta$-unsaturated aldehydes, aryl carboxylic acids have also been observed at $1699 \mathrm{~cm}^{-1}$. The band at $1744 \mathrm{~cm}^{-1}$ was noted for $\mathrm{C}=\mathrm{O}$ stretching vibrations of saturated aliphatic ketones, $\alpha$ halogen ketones, and dicarboxylic amino acids. The removal of color causing pollutants is strongly evidenced by these significant bands appeared in the sludge. The stretching vibrations of $\mathrm{NH}^{+}$, $\mathrm{CH}, \mathrm{SH}, \mathrm{PH}$, and $\mathrm{SiH}$ functional groups are confirmed through the bands appeared at around $2250-2700 \mathrm{~cm}^{-1}$. Other significant functional groups like $\mathrm{O}-\mathrm{H}$ stretching vibration of chlorophenol appeared at $3550-3600 \mathrm{~cm}^{-1}$ and the $\mathrm{O}-\mathrm{H}$ free carboxylic acid groups at $3500-3580 \mathrm{~cm}^{-1}$ were observed. This is also one of the witnesses for removing the pollutants from the wastewater after treatment. There is also a stretching vibration of oximes $\mathrm{O}-\mathrm{H}$, and $\mathrm{Si}-\mathrm{H}$ at $3200-3700 \mathrm{~cm}^{-1}$ was observed. The groups like tertiarybutyl phenols, the bands appeared at $3640-3650 \mathrm{~cm}^{-1}$ and $\mathrm{O}-\mathrm{H}$ stretching alcoholic groups showed that the phenolic/alcoholic groups and are gets delinked due to the effectively treated with the wastewater. These are the evidences for the removal of pollutants from the wastewater.

\section{Conclusion}

The purpose of this work is to overcome the problem of disposal of colored high-strength wastewater released from the integrated pulp and paper industries. This particular research work is achieved by the reduction of the pollution caused due to the diluted chemicals, such as phenol, aromatic primary amines, carboxylic acids, and lignin etc., 
from the wastewater. Moreover, the same research work is greatly useful to conquer the problem of discharging colored wastewater generated from integrated pulp and paper industries. From this work, the color and COD reduction were achieved by maximum removal of pollutants, such as hydrated lignin $(\mathrm{C}=\mathrm{O})$, phenolic hydroxyl groups, chlorinated phenols, carboxylic acid groups, and inorganic functional groups, such as sulphur, phosphorous compounds, etc., which can be highly appreciable and valuable and applicable for the pulp and paper industries. Now, in the present treatment system of this integrated pulp and paper industry, there is no such type of chemicals added to the secondary clarifier unit. Its major role is only to remove the suspended matters. By the addition of the recommended coagulants and flocculants in secondary clarifier unit, the resource recovery is definitely possible. Also to solve the effluent problem, the large quantity of water may be absolutely reused for the other streams/waste facilities and it will not give harmful effects to the environment.

Acknowledgments The authors are thankful to Dr. B. Nataraj and Dr. Moorthi Pichumani, Sri Ramakrishna Engineering College, Coimbatore, India, for providing the FTIR spectral facility. The authors are also thankful to Mr. Arvindh for assistance of this research work.

\section{Compliance with ethical standards}

Conflict of interest The authors declare that there is no conflict of interest regarding the publication of this article.

Open Access This article is distributed under the terms of the Creative Commons Attribution 4.0 International License (http:// creativecommons.org/licenses/by/4.0/), which permits unrestricted use, distribution, and reproduction in any medium, provided you give appropriate credit to the original author(s) and the source, provide a link to the Creative Commons license, and indicate if changes were made.

\section{References}

Ahmad AL, Wong SS, Teng TT, Zuhairi A (2008) Improvement of alum and $\mathrm{PACl}$ coagulation by polyacrylamides (PAMs) for the treatment of pulp and paper mill wastewater. Chem Eng J 137:510-517. doi:10.1016/j.cej.2007.03.088
Choudhary AK, Kumar S, Sharma C (2013) Removal of chloroorganics and color from pulp and paper mill wastewater by polyaluminium chloride as coagulant. Desalination Water Treat 53:697-708. doi:10.1080/19443994.2013.848670

Garg A, Narayana VVVSS, Chaudhary P, Chand S (2004) Treatment of pulp and paper mill effluent. J Sci Ind Res 63:667-671

Kamali M, Khodaparast Z (2015) Review on recent developments on pulp and paper mill wastewater treatment. Ecotoxicol Environ Saf. 114:326-342. web: http://dx.doi.org/10.1016/j.ecoenv.2014. 05.005

Kulkarni SJ, Dhokpande SR, Kaware JP (2013) Studies on flyash as an adsorbent for removal of various pollutants from wastewater. Int J Eng Res Technol (IJERT) 2(5):1190-1195

Kumar P, Teng TT, Chand S, Wasewar KL (2011) Treatment of paper and pulp mill effluent by coagulation. World Academy of Science, Engineering and Technology International Journal of Chemical, Molecular, Nuclear, Materials and Metallurgical Engineering 5(8). web: waset.org/Publication/13277.

Kumar V, Dhall P, Naithani S, Kumar A, Kumar R (2014) Biological approach for the treatment of pulp and paper industry effluent in sequence batch reactor. J Bioremediat Biodegrad. doi:10.4172/ 2155-6199.1000218

Nawaz A, Ahmed Z, Shahbaz A, Khan Z, Javed M (2014) Coagulation-flocculation for lignin removal from wastewatera review. Water Sci Technol 69(8):1589-1597. doi:10.2166/wst. 2013.768

Pretsch E, Buhlmann P, Badertscher M (2009) Structure determination of organic compounds, 4th edn. Springer, Berlin Heidelberg, pp 269-335

Razali MAA, Ahmad Z, Ariffin A (2012) Treatment of pulp and paper mill wastewater with various molecular weight of PolyDADMAC induced flocculation with polyacrylamide in the hybrid system. Adv Chem Eng Sci. 2:490-503, web: http://dx.doi.org/ 10.4236/aces.2012.24060.

Sahoo DK, Gupta R (2005) Evaluation of lignolyrtic microorganisms for efficient decolorization of a small pulp and paper mill effluent. Process Biochem 40:1573-1578

Srivastava VC, Mall ID, Mishra IM (2005) Treatment of pulp and paper mill wastewaters with poly aluminium chloride and bagasse fly ash. Colloids Surf A 260(1-3):17-28

Sunakar P, Chandra PJ, Prasad TU (2012) A Comprehensive approach for the characterization of pulp and paper industry post oxygen stage effluent. Res J Chem Sci 2(7):41-46

Tzoupanos ND, Zouboulis I (2008) Coagulation-flocculation processes in water/wastewater treatment: the application of new generation of chemical reagents. In: 6th IASME/WSEAS international conference on heat transfer, thermal engineering and environment (HTE'08), August 20th-22nd, Rhodes, Greece

Wong SS, Teng TT, Ahmad AL, Zuhairi A, Najafpour G (2006) Treatment of pulp and paper mill wastewater by polyacrylamide (PAM) in polymer induced flocculation. J Hazard Mater 135(1-3):378-388 